\title{
Artistic Impacts: From casual and serious leisure to professional development in disability arts
}

\section{Introduction}

Leisure and disability have more often than not been studied in isolation rather than the more contemporary understandings of interdisciplinarity research bringing together both areas of study, in this case, leisure studies and social model approaches to disability (Aitchison, 2003, 2009; Singleton \& Darcy, 2013). While arts programs have increasingly found favour in disability communities, these programs have historically been oriented towards providing therapeutic and leisure outcomes (Bullock, Mahon, \& Killingsworth, 2010; Solvang, 2018). They have not been taken seriously, in terms of artistic outputs and merits, the deeper benefits for people with disability (PwD), nor for the potential wider social change they can have outside the disability community. This is particularly evident in 'disability arts', which is art work informed by the disability experience and created by PwD (Barnes \& Mercer, 2010; Solvang, 2018). At the same time, there is anecdotal evidence of increasingly sophisticated, ensemble groups of artists with disability (AwD) and nondisabled artists engaged in high production value recreational arts, serious leisure, semi-professional and professional performances and exhibitions. As noted by both leisure and disability studies scholars, participation in all areas of citizenship is important for people with disability as individuals or as part of the group’s active citizenship.

The aim of this paper is to explore how disability arts projects can be categorised as casual leisure, serious leisure (SL) or professional artistic engagement (Stebbins, 1979, 1982, 2005), and examine the kind and reach of their potential social impact (Edwards et al., 2015; Onyx, 2014). In doing so, this paper provides a unique insight into the role of disability arts in the 
lives of PwD, the organisations involved, other stakeholders, and the social impact across these groups and the wider community.

\section{Review of the Literature}

The literature review begins with an examination of disability arts as leisure through the serious leisure perspective (SLP) of casual engagement, SL and professional activity. A discussion of the social impact of arts and disability follows.

\section{The Serious Leisure Perspective for the Arts}

For this study we use a three-level categorisation, based on the typology work of Stebbins (1979, 1982), and Lingo and Tepper (2013). The categorisations provide a useful framework when considering the nature of artistic participation by PwD (Stebbins, 1979, 1982). This categorisation involves at one end the arts as casual recreation/leisure followed by the arts as SL through community cultural development and, finally, the arts as professional career development leading to employment on a casual, part-time or permanent basis.

Stebbins' $(1979,1982)$ early work on amateurs in the arts, acknowledges the conceptual importance of the space and place between leisure and work and the conceptual difference between amateurs, SL pursuits and professionals. In a professional-amateur-public (P-A-P) situation, amateur participants look to professionals regarding standards. The categorisations encompass the SLP which has been developed and promulgated by Stebbins since the 1970's (Elkington \& Stebbins, 2014; Veal, 2017). Participation in arts can be considered a subtype of amateur participation, which, in turn, is a subtype of SL (Elkington \& Stebbins, 2014). These categorisations are reinforced with the work of Lingo and Tepper (2013) who articulate some of the characteristics of arts-based careers and creative work in general. 
Participation in the arts for PwD has been shown to take the following forms: art as therapy focusing on the psychosocial benefits (Chancellor, Duncan, \& Chatterjee, 2014). Casual participation as a form of leisure that are short lived, fleeting and require little training with the benefits of serendipity, edutainment, regeneration, the development of personal relationships and improvements in wellbeing (Elkington \& Stebbins, 2014). However, SL requires commitment, skill and knowledge development (Stebbins, 2005), while paid work in a professional setting involves the development of a distinct career identity (Lingo \& Tepper, 2013). PwD and the nondisabled regularly move between the recreational, SLP and career development (Victorian Office for Disability, 2010).

Art as a SL activity has been used both to examine the arts and disability separately and focusing specifically on disability arts programs (Anwar McHenry, 2011; Conroy, 2009; Patterson, 2000; Stebbins, 2000). It draws on both Stebbins’ work on the SLP (2007) and Lingo and Tepper’s (2013) understanding of community cultural development, where skill acquisition for participation through training by paid or volunteer professional artists is a priority and where the programs which have community strengthening and social inclusion outcomes are given higher priority. PwD have found that SLP activities such as artistic endeavours can provide meaningful activity, personal rewards such as self-actualisation, a sense of purpose, social rewards through group accomplishment as well as providing them with a positive alternative to paid employment. In so doing the SLP challenges assumptions that paid workforce participation is the only viable option for work in a neoliberal society and postulates that SLP can provide similar benefits (Patterson, 2000). 
The next level of categorisation in the typology is arts as professional engagement. The role of creative work in providing work for PwD is identified in the literature (Hall \& Wilton, 2011; Patterson, 2000), as well as the potential for artist endeavour to provide meaningful career development amongst AwD (Boeltzig, Sullivan Sulewski, \& Hasnain, 2009). For example, Boeltzig et al. (2009) discuss the educational and career pathways of 47 young AwD. They suggest that the professionalization of the sector can occur if inclusive arts programming and education are promoted more widely and training is accessible to all. Career development for AwD would appear to be an important avenue for further investigation.

The categories of creative participation discussed in this review are by no means discrete or fixed. There can be overlapping between intentions in each category and, increasingly, as the disability arts sector evolves and grows. As noted by the arts community in general, there is a major economic issue with continuity of creative opportunity, work and employment where artists maintain their practice without paid arts employment and supplement through other employment opportunities (Baumol \& Bowen, 1966). Hence, there is evidence of movement through the levels as a form of 'creative continuum' by artists, with or without a disability, at different times during their artistic ‘careers’ (Throsby \& Zednik, 2011; Victorian Office for Disability, 2010). A greater understanding of this creative continuum for AwD will enhance our understanding of the impact of disability arts not only on individuals and their families but also on the wider community.

\section{Social Impact of Arts and Disability Arts}

Whether disability arts is regarded as casual leisure, SL or professional engagement will depend largely on the kind and reach of the impact it has. All forms of arts engagement are 
likely to lead to positive outcomes, but the nature and reach of these outcomes will differ. Social impact, and its measurement, involves a multifaceted set of relationships. While 'social impact' may be defined in many ways, the contexts in which it is used shares a number of common themes (Edwards et al., 2015; Onyx, 2014). The first is that social impact is linked to social capital, and the generation of increased (or decreased) levels of social, cultural and human capital (e.g. technical skills and leadership), within their relevant constituent communities (Edwards et al., 2015). The second is that, in relation to programs, social impact refers to wider social effects that extend beyond a program’s immediate objectives (Onyx, 2014). The third common theme is that social impact refers to the effects of a program on the wider community, and includes intended and unintended spill-over effects (Onyx, 2014). Most recently work on social impact of the arts and disability has been conceptualised as an important consideration for active citizenship of PwD (Onyx, Darcy, Grabowski, Green, \& Maxwell, 2018). By active citizenship we mean participation and engagement in all areas of citizenship and civil society that underpin the spirit and intent of the UN Convention on the Rights of Persons with Disability (2006).

Matarasso’s (1997) ground-breaking UK study was arguably the first significant empirical investigation of the social impact of community arts. From Matarasso’s work involving community participation in general, broader research themes were identified including: personal development; social cohesion; community empowerment and self-determination; local image and identity; imagination and vision; and health and well-being. There is a growing body of evidence that participation in community-based arts, leisure and recreation projects provide many individual and community benefits (Evans, Bellon, \& Matthews, 2017) including a range of social impacts (Onyx et al., 2018), for example, improvements in educational attainment (Bamford, 2006), personal health, social capital, tolerance, and cross 
cultural understanding (Mulligan et al., 2007). Additionally, participation has been shown to promote creativity and economic independence (National Advisory Committee on Creative and Cultural Education, 1999), which benefits the individual, as well as their audience and fosters wider community engagement.

Very few studies have specifically looked at the social impact of disability arts. In one of the few studies, Selkrig's (2011) found that there were significant changes for the identity of the AwD as well as wider impacts for the community and their understanding and perception of disability. For the AwD, this included being identified for their artistic ability first and foremost rather than being defined by their disability. From a community viewpoint their perspectives were enlightened by a combination of the abilities on show and insider insights into understanding disability. This work has informed government approaches where arts and disability are seen as part of professional artistic endeavour beyond providing just meaningful leisure engagement. The Victorian Office for Disability (2010, p. 51) offers a creative continuum similar to Stebbins (1979, 1982, 2007) and Lingo and Tepper (2013) with arts participation moving from: therapeutic; recreation; community cultural development; and professional career development.

\section{Research Design}

With this background, the aim of this paper is to explore how disability arts projects can be categorised as casual leisure, serious leisure (SL) or professional artistic engagement, and examine the kind and reach of their potential social impact. To achieve this aim, we examine the overall project characteristics, core outcomes, social impact and active citizenship factors as evidenced through an abductive research design process following a qualitative case-based approach at an individual and organisational level. The abductive approach involves a logical 
interpretation of the three projects, which begins with observation (through a scoping process) and then seeks to find the most likely explanations. An abductive research design seeks to look beyond individual qualitative case studies through an iterative process to draw conclusions on collective cases (Locke, 2010).

As identified in Table 1, the cases were divergent in their context and abductive processes to allow collective understandings to be developed. The iterative nature of the process allows for the qualitative cases to be critically analysed, deconstructed and reconstructed to generate new meaning (Baxter \& Jack, 2008; Bryman \& Hardy, 2004; Eisenhardt, 1989; Stake, 1995; Yin, 2014). The abductive approach requires the following criteria to be met (Yin, 2014): the research seeks to understand the how and why of the project's contribution towards casual, SL or professional engagement; the research process is observant of the context in which stakeholders find themselves and does not try to change or manipulate the behaviour of those in the study; the collective projects are relevant to the underlying creative continuum being studied; and the arts context of the projects is inseparable and interconnected to the participation of AwD.

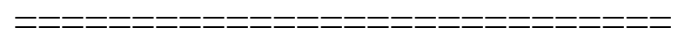

Table 1 About Here

The research took place from 2012 - 2014 and involved organisations based in New South Wales (NSW), Australia in the arts and/or disability sectors. The research was conducted by a team of six academics from a research centre at an Australian university and was supported by a state government partnership with the arts and disability sectors (Onyx et al., 2018). The aim of the partnership was to deliver programs that increased opportunities for PwD to participate in arts and cultural activities; supported the development of excellence in the arts; 
strengthened professional networks in the arts and disability sectors; produced collaborative partnerships; and supported creative practice for PwD (Onyx et al., 2018). The research team had no prior affiliation with the funding bodies and were engaged through a competitive tender process (Onyx et al., 2018). This paper adopts a SLP that has not been considered in the previous paper.

The organisations from the arts and disability sectors applied for a competitive grant round from a state government to provide arts workshops, programs and performances for PwD. Central to the application process was track record in providing inclusive arts practice for PwD. The 12 projects selected were considered on track record as best practice for inclusive art practices for PwD. The selection of the projects was outside the control of the research team, whose focus was to research the social impact of the disability arts projects rather than to document the inclusive practice of the organisations, which was documented in the application process.

Ten case studies were prepared to measure the outcomes of the projects based on a model of social impact and active citizenship (Edwards et al., 2015; Onyx, 2014). Three of the ten case studies are reported on in this paper. While all cases were positioned somewhere along the SLP typology after analysis (Table 1), the cases were selected because each had a similar geographic location (i.e. they were all in regional areas of NSW) and artistic performance characteristics (i.e. they had a performing arts focus) but differed in their audience and project longevity. These latter two variables are important considerations when comparing the social impact and active citizenship factors across cases. 
A qualitative, case study methodology was adopted for this research because it allowed for a detailed analysis of the three projects, within their contexts for individuals and across the different projects (Veal, 2011). Using case studies provided the opportunity to engage, in detail, with a range of data collection methods involving multiple data sources. For each of the case studies the data collection methods included: (1) project observations, two or more researchers attended workshops/rehearsal/performances to observe the projects in action and to gauge a sense of audience reaction. The observation led to the identification of key informants and stakeholders, (2) in-depth interviews and focus groups with these key informants including: project managers, facilitators, participants, artists, audience and participating organisations' staff members. Each interview explored the informant's contribution to the project and their perception of the positive and negative outcomes, (3) content analysis of audio-visual material, media reports, social media e.g. Facebook, websites, internal organisational and project documents, and (4) audience interview/survey (open-ended questions).

The quantity of data collected in each project varied depending on availability, the timing of the project (i.e. which point of the creative process it was at), and saturation of themes (i.e. more participants/informants were sought in some cases). This data mix allowed for the ‘triangulation’ of data (Stake, 1995; Yin, 2014), that is, the exploration of the phenomenon at the centre of the research through more than one lens or data source. This, in turn, enhanced data credibility and led to reliable and robust results that were used for the interpretation of artistic engagement factors and indicators for the projects.

In-depth interviews and focus groups were recorded and transcribed. The resultant text was prepared for data analysis using the NVivo (QSR International, 2012). The text was 
coded to the social impact and active citizenship factors (Edwards et al., 2015; Onyx, 2014). These 10 factors are: program activity, welcoming, belonging, program social values, individual social values, program networks, individual networks, skills and creativity, program wider social impact, and individual wider social impact. Two researchers were primarily responsible for each case study, with the remainder of the research team having secondary responsibility for the cases through reading the artefacts, transcripts and other data. The coding process was firstly an individual process of each of the research team prior to meeting to discuss the codes that each person developed. This opened a conversation as to the trustworthiness of each code as an example of social impact and provided a basis for construct consensus on the coding across all the case studies. During this conversation, the two primary researchers drew on their observation of the case interactions (notes taken and debrief meetings with the research team), while the remainder of the research team were objective, only having vicariously observed the projects (i.e. through hearing and reading accounts of performances). Audio-visual material, internal documents and media reports were manually coded to the same factors. Once each individual project was coded, all projects (see Table 1) were compared thematically to examine collective impact. Table 1 is a summary of a substantial research report provided to the funding body including a detailed 20-page analysis for each case study that form the basis for collective impact findings.

\section{Results}

Three case studies which represent projects across the SLP creative continuum are outlined and discussed in relation to the characteristics of the projects, outcomes and individual and wider social influences. The findings are organised beginning with a brief description of the projects prior to examining the social impact and active citizenship factors across cases. 


\section{Project 1}

Project 1 is presented as an example of casual leisure engagement. The project involved a multi-arts program of music, dance, visual arts, storytelling workshops and performance, linking PwD in multiple regional areas and was facilitated through a regional arts board. The arts organisation worked to promote, educate and facilitate arts and cultural development in the surrounding rural communities. Key strategic stakeholders in the organization's work included the creative industries, universities, young people, arts, health and disability services organizations and Aboriginal arts. The project entailed $38 \mathrm{PwD}$ involved in a number of music, dance, visual art workshops and a visual arts exhibition featuring artworks from the project. The project climaxed in a multi-disciplinary performance which focused on the theme of dreams. This took place on a weekday afternoon in one of the three regional towns involved and was attended mostly by family, friends and other Disability Services Organisations (DSOs). DSOs in the Australian context support PwD to develop skills to participate and contribute to the wider society through choice, inclusion and education. The PwD involved in the production were mostly from these DSOs and the majority did not have previous training in the arts. The social impact was restricted to the family and friends of the participants.

\section{Project 2}

Project 2 demonstrates SL engagement. It involved the collaboration between a theatre company and DSO located in a large regional town. The outcomes from the project were exhibited more extensively than Project 1 . The program was an extension of the existing partnership arrangement between the two parties which had been established over several years. The DSO, founded in the 1970s by a group of parents of PwD wanting services in their local area for their sons and daughters, was expanded in the 1990s to include sport and 
recreation programs. Currently there are over 13 programs running under this umbrella with over 170 participants. The project created a rehearsal-ready play for production for AwD which formed part of the theatre company's 2014 season and, in doing so, provided the first serious mixed abilities work for the company. Additional workshops occurred prior to the production and these were held onsite at the theatre company. The group had multiple performances and involved an extensive network of stakeholders engaged with this program.

\section{Project 3}

Project 3 was considered a career development project as it consisted of a professional theatre production with a well-defined creative process. The project involved a professional mixed ability sound ensemble (band) under the direction of a theatre company with two directors located in a regional town. The band members were six AwD with a range of impairments that came together to develop a production through an extensive workshop program in collaboration with a local school and subsequently the ensemble went on tour to Sydney. The group used dance, circus, visual arts, live music, a range of interesting locations, audience participation and technology to tell a story. Essentially the project recognised the artistic ability of the AwD by providing them with a variety of artistic activities which would develop their artistic skills and move beyond an individual location. The results of the production were numerous and extended far beyond the disability services sector and local performing arts to the wider communities in both regional areas and urban settings. The national touring production was based on the commercial sale of tickets in conventional performing arts venues and involved the payment of AwD at industry standard rates.

\section{Social Impact and Active Citizenship Factors}


Each of the three projects is now analysed in relation to the individual and organisation level factors: welcoming and belonging, social values, skills and creativity, networks and partnerships and wider social influences. We include direct quotes from in-depth interviews, focus groups, notes from observations of creative development and performance sessions, and other collected evidence to support the project's connection to the factors.

\section{Welcoming and belonging}

Welcoming involves organisations who are staffed by hospitable people and offer safe and inclusive environments that accept PwD. Belonging, on the other hand, is an individual-level factor, indicating trusting friendships amongst a group of supportive people with common goals. In Project 1, participants were contacted through their DSOs and from local communities using open letters, which can be considered a 'cold call'. The individuals that responded were bought together on a limited number of occasions to form an ensemble culminating in a one-off performance. Researchers observed little evidence of participants developing strong feelings of belonging to the organisation or project (e.g. body language, banter, friendships that extended beyond the artistic space). The afternoon weekday timing of the event limited wider engagement and there was no follow up funding to continue developing the initial work after the grant.

In contrast, an important feature of Project 2 was the ability of the project to engage and include AwD in the development of the creative process together with nondisabled artists/production crew of the theatre company. The DSO in Project 2 had traditionally been a very inclusive organisation and the theatre company had taken a greater interest in providing mixed abilities workshops and performances. This philosophy had also been instilled within the organisational culture of the theatre and was reflected in the programs offered to 
participants. The participants of the production and other projects in Project 2 were made to feel welcome, included and part of the community:

I mean as it relates to the [DSO] our whole philosophy is creating an inclusive world and it's about getting the guys out in the community (and) being seen... when we bring them to this situation, it's not a case of here are some actors with disabilities, they're just actors... and by doing that it enables the guys to get that sense of confidence (DSO employee, Project 2)

Individual members of the drama group can be seen reaching out to others in the disability community to join in. Robert, one of the original participants who had been involved for over 20 years, explains that:

I found out about it through my friend [Rana] who was in the drama group at the time... She goes to me, "Oh you should join the [Name] they're the most awesome drama group ever”. (Participant AwD, Project 2)

In Project 3 the production was developed because the regional arts organisation was interested in working with $\mathrm{AwD}$ in the local community to devise a unique production over an 18-month period.

We like to try to bring the community with us of course in the making of work, whether it's through direct participation, through getting stories from the local community or engagement through sharing of work or showings or whatever, but in this case, it was workshops with, what we called, civic space. (Project Organiser, Project 3) 
Project 3 was a collaboration involving AwD and nondisabled working in various artistic mediums. The core of the group was made up by a band of musicians who had been working with each other for some time on the creative process and they worked together as a group with other participants towards a common purpose.

I think we are all really close now because we've been together for a while, and this was just another thing that bought us even closer together, because we really did support each other... Just the natural bonding that comes off it, we are definitely closer because of the experience. (Musician/Actor nondisabled, Project 3)

\section{Social values}

There are several individual social values (e.g. feeling respected) and communal social values (e.g. challenges stereotypes of AwD) which are evidenced in the case studies. According to the model of social impact (Edwards et al., 2015; Onyx, 2014), the development of a sense of social shared responsibility is critical to the development of wider social impact. However, the results show that in a project which is categorised as casual leisure, this value is absent (Project 1). The Project Organiser in Project 1 suggested that "Participants gained pride from their significant contribution to the recording and they also remarked about the opportunity to make music with new friends”. In a follow up interview, she stated:

those girls that did the movement, they were so proud of themselves afterwards. One of them lives around the corner from me and I see her a bit, and she always still comes and chats to me when I see her. It was that sense of achievement that feeds into self-esteem in really important ways”. (Project Organiser, Project 1) 
A participant of the project commented on her experience on Facebook, stating, "it was very cool" (Social Media Post). In this project PwD had been brought together without a previous history of working together. Individual self-development and the beginnings of collaboration were the major outcomes with the performance itself, an end rather than a means. However, there was no capacity to further develop this experience of collaboration or shared group responsibility.

In Project 2 common social values which involve communal qualities and beliefs were exhibited by the actors/members of the two organisations involved in the project. These values are created, developed and involve respect, trust, support, and reciprocity. In particular, the AwD mentioned kindness, respect and consideration resulting in friendships and other supportive relationships inside and out of the project. The DSO was described by the AwD as promoting feelings of togetherness with participants explaining that they felt like a family. Charles, one of the actors, explains “they make you feel welcome. Like someone who's feeling insecure, all they'll say we're all here to help each other and I'm helping you. I feel at ease, I'm part of the group" (Participant AwD, Project 2). The consensus from the participants is that the DSO workers are friendly and show an interest in their lives and their feelings. The participants in the DSO’s workshops explained that friendships commonly develop.

In Project 3 the artists in the regional arts organisation and the project team were passionate about making art with the community and with AwD. As the Creative Director explained, the project is "all about the art really and the fact that we are making it inclusive and accessible, those sort of things as I mentioned are part of our process anyway”. (Creative Director, Project 3). This was elaborated by one of the theatre's project team members: 
The other thing that's really an important part of this is that we also want to encourage all members of our community ... to feel like they can access what goes on at this city hall artistically, whether it's a piece of theatre, a piece of music, a piece of dance, that people feel like they can make a connection to that, come and view something, just for the pure creative joy of it. (Project Facilitator, Project 3)

The production was central to the regular theatre season,

We are taking time with this and we are putting so much behind it because we want to make a work that we have the general public come and see... So, to make something for, let's say, call it the main stage, for our season, that's what we are saying, we are making something worthwhile. (Creative Director, Project 3)

To this end the production was successful through selling out the local season and then going on a tour of major metropolitan and rural centres.

\section{Skills and creativity}

PwD develop individual, intrapersonal and interpersonal skills through their involvement with the projects. In Project 1 the artistic, dance, movement and music skills as well as the development of innovation and creativity were key project elements. A comment by the project organiser illustrates this achievement of skills and creativity:

The dancers worked enthusiastically with focus, commitment and a strong sense of positivity around trying something new. They have been very generous with giving creativity within the process. Participants gained confidence, improved mobility, venturing outside their usual service providers and had a platform to share something about themselves. (Project Organiser, Project 1) 
In Project 2 the professional theatre company involved had begun to integrate their work with AwD into their core practice. Through the workshops, they have been exposing AwD to professional practice and encouraging them to develop skills associated with the theatre. The key outcome of the creative process was professional theatre in a conventional venue with ticket sales. The creative and professional acting skills of those involved were enhanced through the creative process. The five actors and support crew showed enthusiasm and dedication for the process and all grew as a group. In describing her involvement Rana explained:

The best thing about it is expressing yourself with what you have, basically, in yourself and believing in what you do and follow your dream. And it's just amazing feeling that when you see this, people out there, please, follow your dream, 'cause this is part of my dream. (Participant AwD, Project 2)

Eddie’s involvement in Project 2 has led to professional aspirations.

I've actually got goals to get into filming now and I've started writing a story or actually a screenplay. Because I've finished writing a story itself which took approximately nine years, but now I'm onto the screenplay. That will be very funny. (Participant AwD, Project 2)

A key outcome from the production in Project 3 was the professional skill development of the performers. The five members of the group are musicians; four have a disability and had never acted before. As well as the acting skills that they had acquired, the musicians with disability enhanced their intrapersonal and interpersonal skills: 
One guy in particular, the guy who is autistic, he's been going to a day service for most of his adult life. He hadn't been challenged much in his adult life to go beyond what he thought he was possible of doing, and for him going through this was an amazing process for him. Out of that he's gone on to do other stuff. (Musician/Actor nondisabled, Project 3)

One of the Project 3 theatre team members acknowledged the development of the actors throughout the creative process: “It's great to see people develop potential - I get a little bit teary when I talk about that but that's one of the coolest things about working with this mixed ability ensemble."

\section{Networks and partnerships}

Networks at the organisational level indicate that a program can link with many partners and create relationships, which benefited artists and other participants with disability. Networks at the individual level involved the PwD being able to form new relationships and professional networks for future artistic endeavour. Project 1 involved a range of partnerships between the arts organisation and other individual artists and organisations. These partnerships were fundamental to the success of the project allowing the project to operate across a wide geographic area. This required a network to assist with the logistics to ensure a smooth roll out.

So, there wasn't one particular partner that worked in depth, as I said, there's probably about six organisations that we already have relationships with (Project Organiser, Project 1).

In Project 2 the partnership between the DSO and the theatre was formed prior to this project. The partnership gave AwD the ability to take their interest in drama from a more leisure 
orientated engagement to a serious level. It is a partnership that benefits all parties with strong bonds between the two organisations.

It's perfect now they [the theatre group] run the drama side in regard to enhancing the skills developed in that, and then we provide ... [a support member who's] able to manage any participant issues that may arise at any given week, so ... And it just complements one another really. (DSO employee, Project 2)

Community engagement through partnerships was a key theme in Project 2. Partnerships with other theatre groups are acknowledged as well as relationships with the local university, with other non-profits and local sponsors such as the Council and commercial sponsors.

In Project 3 there were several individual and organisational partnerships to develop from the production which assisted in the project achieving its outcomes. One of the collaborations allowed the production to tour to a major metropolitan city as part of an urban theatre project which gave the musicians useful contacts to develop their future artistic endeavour. The musicians in the project partnered with schools and DSOs in the community, these relationships brought benefits to the AwD:

The local organisations already run arts programs but what was exciting here was putting a wide range of local and national artists together - an opportunity for them to see what is possible out of that collaboration. (Project Facilitator, Project 3)

\section{Wider social impact}

This factor involved varying degrees of engagement of the organisation and the individual beyond the project teams and, hence, social impact. In Project 1 the facilitators who worked on the project always had high expectations of what would be achieved from the outset. There was 
a shift in the attitudes and expectations from some of the DSOs about their participants' abilities for dance and movement. Wider social impact was limited; one of the DSOs chose to fund ongoing dance workshops internally within their organisation, but not to all those involved in the project. Other social impacts were evidenced but again the recipients were limited to the DSOs:

We have also shared the outcomes widely through the short film made about the project and this has also received extremely good feedback. Perhaps most importantly, some of the disability services have wanted to keep similar work going and are now more aware of a greater range of possibilities for workshops. (Project Organiser, Project 1)

However, the afternoon performance time of the show was a limiting factor in terms of impact. Although an ideal time for DSOs it was less convenient for other potential performers or audience members with work commitments. Another issue highlighted by the facilitators was the lack of ongoing opportunities for many of those AwD involved in the performance due to funding and long travel distances associated with rural Australia. While meaningful for those involved in the project, the focus was on the single arts performance without any requisite provision for creative process co-creation with AwD. As the project was a collaboration between DSOs, there were few opportunities for the participants to engage with the wider arts community or the wider local community.

In Project 2 the social impact within the wider community was discussed by participants, professional artists and audience members who included school children and season ticket holders. It included the development of an artistic reputation of the theatre and DSO in the wider disability community, the arts community and the local community including schools, 
Well I think one good thing is it's helping the wider community find out the truth about people with disabilities. Just because a person's got a disability that does not mean to say that they are no good for society. And disability affects you only in the way that - like the way a disability affects you just depends on what type of disability you have, as well as how severe it is too. (Participant AwD, Project 2)

Furthermore, school children attending the performances (mainly year 12 drama students) expressed their appreciation of the performance. One student stated, "I really loved the show... the actors who had disabilities were really good, I would come again”. This response was typical amongst the school children who had not previously experienced a performance involving AwD. The inclusion of the production in the wider theatre program season enabled a wider community audience to experience the production. This wider audience included school children, regular theatre-goers with season tickets as well as family and friends of the cast. Eddie (AwD) explained how he uses these wider connections he has made to advocate for AwD. He stated that he has had conversations with local community members about "the things that are going on in the country at times which concern us. And I know how to speak up for our rights too, because I know a lot about them".

Project 3 engaged local community members in its activities and was shown both locally, to regional audiences, and in Sydney. The audiences consisted of the general community and theatre subscribers as well as family and friends. There was a lot of positive feedback sent to the arts organisation after the performance. For example:

Last night I had the privilege of attending this amazing performance. I am 72 years old and attended to support the group ...thinking that words like contemporary and virtual world would simply not be my scene. To use a modern phrase, I was blown 
away by the production and would like to congratulate ... all concerned with this truly outstanding show. The combination of music, video projection and wonderful acting in such a simple setting was a riveting performance. I hope this show continues to be seen by many Australians and that the group continues to grow in performances. WOW!! (Audience member, Project 3)

\section{Discussion}

The discussion draws together the key considerations of the findings to address the aims of the paper, that is, to explore how disability arts projects enable inclusive opportunities for casual leisure, SL and professional artistic engagement, and the kind and reach of their potential social impact. The categorisations from casual leisure, SL and professional career development draws on (Stebbins, 1979, 1982, 2005, 2007) important early work on the SLP regarding amateurs and professionals where the distinction between leisure and work has implications for the field. The abductive case study method was also an important contribution to discussions about the interaction between leisure and disability. This study has brought the two together as argued by scholars (Aitchison, 2003, 2009; Singleton \& Darcy, 2013).

The three projects had much in common. None concerned arts as therapy. Each project was held in a regional area of NSW, with PwD from community settings. Each had a similar performance outcome (theatrical) and involved PwD as a core to the performance outcome. Yet, the way that each project was operationalised showed important differences in terms of the way that the projects and stakeholders interacted, and the project outcomes and impact. We will now examine the nature of the projects' engagements and their ability to produce social impact and change. 
Project 1 demonstrated a classic leisure involvement by PwD where they were participants in the program but not collaborators in the artistic process. As artists they were instructed by a well-rehearsed DSO which made decisions about their artistic involvement and what the 'show' was to express. The social impact, consistent with casual leisure included personal development outcomes for the individual, a sense of pride and achievement, and an extension of their social network. The wider social impact of the program was less well developed as the ensembles created during the project were not sustained after the project primarily because of geographic challenges and funding. This short lived, fleeting engagement for PwD reflects Elkington and Stebbins’ (2014) casual leisure category. The power and control were centred with the DSO with little opportunity for the development of individual or collective agency by the AwD. While the performance did challenge perceptions of AwD, its weekday scheduling also limited the wider audience impact.

The project design which engaged participants from DSO day programs was a characteristic commonly found by the Victorian Office for Disability (2010) which indicated that participants and carers treated the activity as a pastime to improve social engagement skills rather than an important leisure activity. As noted in the literature review, SL potentially provides much broader social impact, both for the individual concerned and for the wider social context. There is the potential for ongoing personal development, skill development, and wider engagement across time and across social contexts. Wider creative initiative across networks may lead to broader shifts in social attitudes to AwD.

Project 2 moved into the realms of SL through its established partnership between the theatre company and the DSO. This partnership was shown to build on the relationships and trust 
developed on a number of previous projects involving AwD working on their skills as actors and developing creative practice. These relationships enabled the creation of a safe, secure atmosphere for the participants. These trusting relationships are underpinned by a welcoming ideology. AwD are encouraged and enabled to participate in a substantial creative process which results in a successful integration of productions. The productions involve both AwD and without disabilities in authentic collaboration. This creative process provides the artists with a real sense of purpose and meaningful activity (Patterson, 2000) which are distinguishing qualities of SL (Elkington \& Stebbins, 2014).

Project 2 and 3 findings showed substantially different organisational attitudes, collaborations and performance vision than Project 1 . Both these projects demonstrated that instances where multiple organisations with different purposes collaborate, there are clearly articulated artistic processes. They had a history of creative development having received previous funding and artistic development, and were located within an ordinary performance space. Critically, PwD were part of the artistic process where they actively contributed to the ideas, production and performance.

Project 3 displayed a much greater development of individual factors such as the development of professional skills of the AwD and the passion for making art. This project included all the characteristics of SL and extend beyond SL through the success of the production based on professional production qualities and audience satisfaction. This contributed to the extended life of the project and the wide variety of audiences it touched. It was clear that this project engaged a well-established band of AwD who loved their art making and were engaged professionally inside and outside of this project. Further, their engagement with a local school as part of the creative development process provided an edge 
where they were taking expertise to groups who would normally regard PwD as recipients of support.

The wider community impacts found commonly in Projects 2 and 3 support Selrig (2011) who found that because of their participation in arts projects, artists found their own identities being disrupted while the views of others were also challenged (e.g. who PwD were), while a deeper understanding of disability was developed within the broader community. Selrig's (2011, p. 587) other observation was that through their interactions with a broad range of people within the community, the AwD “developed a sense of belonging, an acknowledgement of who they were and a deeper understanding about themselves at several levels”. These changes and benefits are also common to other community arts projects (McQueen-Thomas \& Ziguras, 2002; Mulligan et al., 2007; Myer, 2002; Rogers \& Spooks, 2003). They go beyond the measure of 'artistic vibrancy' as an organisational indicator or a trait of the artist, and instead, relate to the systemic impact that artistic and cultural expression have in constructing the social within the individual, the group and the wider community. In essence, the AwD individually and as a collective developed an agency to create, control and direct the artistic process and vibrancy of their performances.

The meaningful career development amongst AwD in Project 3 reflects and substanitates earlier research by Matarasso (1997), Boelzig et al. (2009), Hall and Wilton (2011) and the Victorian Office for Disability (2010) which also provides evidence of the social and individual impact of art as a professional activity for PwD . In doing so, it also extends aspects of this work where $\mathrm{AwD}$ in their own right sense the opportunity for an artistic career. As noted in the literature, an artistic career is characterised for most as a movement between amateur, semiprofessional and professional engagements due to the precarious 
nature of the work, and AwD face the same challenges as artists nondisabled (Baumol \& Bowen, 1966; Throsby \& Zednik, 2011).

The outcomes from Project 3 also support earlier research which indicates that resources, public presence and greater community awareness are required to create the circumstances in which social capital, can be optimised (Matarasso, 1997; Hall \& Wilton, 2011). As indicated in the literature review, maximum social impact occurs with the increase of social and human capital which is necessary for 'employment opportunities' and ‘career-building'. Project 3 pushed the boundaries into paid engagement with the travelling performance schedule after the project performance while Project 2 also had potential career opportunities for their AwD. Although the arts are typically identified as a difficult employment market, this raises doubts about using 'employment' as a measure of 'project success' (Band, Lindsay, Neelands, \& Freakley, 2011). However, in conjunction with personal development, providing a route to employment is an important consideration for a project's possible outcomes on AwD because of the poor participation rates in employment (ABS, 2015).

Social capital is created when relations among people change to facilitate action (Coleman, 1990), and is as much about the changes that take place in nondisabled participants as it is about PwDs. Project 3’s AwD had already broken this ground with their previous professional gigs. They were matched with a commercial theatre that had a hard-nosed approach to taking on any performance production, in that they needed to see that the show had the potential to be commercially viable to tour other regional or metropolitan venues. Making professional performance a standard aspiration brings it closer to the reach of AwD when they are producing work regarded for its creative process and integrity. This brings AwD in contact with a whole range of new professionals, their networks and the exposure of 
touring to other areas where they are not known where new opportunities may become available.

The key developmental factor of wider social impact involves a multifaceted set of extended relationships. However, no matter how varied the contexts they all rely on the factors of belonging, the development of social values, skill development, network formation, all leading to wider social impact (Edwards et al., 2015; Onyx, 2014). The analysis of social impact and active citizenship factors within each case provides evidence of the way in which disability arts projects enable inclusive opportunities from casual leisure to SL to professional artistic engagement. As the case studies demonstrated, key factors needed to be in place (welcoming and belonging) for the sophistication of the creative process to develop higher level artistic skills and project outcomes. This movement through the creative continuum was also evidenced by the longevity of the ensembles, multiple rounds of funding, rapport between AwD and nondisabled, and a creative inclusive vision that took casual engagement to SL and beyond.

\section{Limitations}

The research team note limitations to the paper. The logistics of time and distance limited access to participants. Foremost given the nature of the projects was being able to access all people during the times that they were available in the areas literally spanning the geographic size of the UK. Understanding impact requires the temporal dimension where it would have been desired to spend a longer time post project to pick up on other impacts. Research could also explore inclusion for PwD using the SLP across a wider range of art related fields. 


\section{Conclusion}

Each case representing a major arts and disability project was categorised using the SLP typology, which was informed by an active citizenship and social impact frame. By considering the projects in this way this paper has identified differences in individual, organisational and social impacts. The impacts for both the individual and the organisation increase as participants with disability become more seriously involved in the creative process. Participation in artistic activities for PwD has the potential to lead participants on the creative continuum from casual, serious or professional career development (Stebbins, 1979).

The findings have demonstrated the possibilities for PwD wishing to develop their creative potential. It is not the purpose of this study to "evaluate and judge" individuals, organisations and creative outcomes. As long as PwD have a choice to pursue the arts for in a way in which they want to be engaged, the outcomes they wanted to achieve and with those whom they wish to associate then it is best left to them to decide. From an organisational perspective, it is important to create an inclusive space and place to skill and empower PwD's voices to cocreate and collaborate on the creative process for productions.

The findings have shown that with professional artistic development some PwD may become professional AwD. This transformation of PwD participating in a leisure activity (arts) to an AwD occurs when the individual and collective group seek to attain excellence beyond participation. At the career end of the SLP, AwD and nondisabled artists have the same opportunity for employment in an industry with difficult continuous funding circumstances where artists' careers iteratively move along a creative continuum as project and funding circumstances change from their casual leisure beginnings. Whatever engagement the individual chooses, the projects have demonstrated their artistic impact through their abilities. 


\section{References}

Aitchison, C. (2003). From leisure and disability to disability leisure: developing data, definitions and discourses. Disability \& Society, 18(7), 955-969.

Aitchison, C. (2009). Exclusive discourses: leisure studies and disability. Leisure Studies, 28(4), 375-386.

Bamford, A. (2006). The Wow Factor: Global research compendium on the impact of the arts in education. Berlin: Waxman Munster.

Band, S. A., Lindsay, G., Neelands, J., \& Freakley, V. (2011). Disabled students in the performing arts-are we setting them up to succeed? International journal of inclusive education, 15(9), 891-908.

Barnes, C., \& Mercer, G. (2010). Exploring Disability. Cambridge: Polity.

Baumol, W. J., \& Bowen, W. G. (1966). Performing Arts - The Economic Dilemma: A Study of Problems Common to Theater, Opera, Music and Dance. New York: Twentieth Century Fund.

Bullock, C. C., Mahon, M. J., \& Killingsworth, C. L. (2010). Introduction to recreation services for people with disabilities: a person-centered approach: Sagamore publishing.

Chancellor, B., Duncan, A., \& Chatterjee, A. (2014). Art therapy for Alzheimer's disease and other dementias. Journal of Alzheimer's Disease, 39(1), 1-11.

Coleman, J. S. (1990). Foundations of Social Theory. Cambridge MA: Belnkamp.

Edwards, M., Onyx, J., Maxwell, H., Darcy, S., Bullen, P., \& Sherker, S. (2015). A Conceptual Model of Social Impact as Active Citizenship. Voluntas: International Journal of Voluntary and Nonprofit Organizations, 26(4), 1529-1549.

Elkington, S., \& Stebbins, R. A. (2014). The serious leisure perspective: An introduction: Routledge.

Evans, T., Bellon, M., \& Matthews, B. (2017). Leisure as a human right: an exploration of people with disabilities' perceptions of leisure, arts and recreation participation through Australian Community Access Services. Annals of Leisure Research, 20(3), 331-348.

Hall, E., \& Wilton, R. (2011). Alternative spaces of 'work' and inclusion for disabled people. Disability \& Society, 26(7), 867-880.

Lingo, E. L., \& Tepper, S. J. (2013). Looking back, looking forward: Arts-based careers and creative work. Work and Occupations, 40(4), 337-363.

Locke, K. (2010). Abduction. In A. J. Mills, G. Durepos \& E. Wiebe (Eds.), Encyclopaedia of Case Study Research. New York: Sage.

Matarasso, F. (1997). Use or Ornament?: The Social Impact of Participation in the Arts. Stroud, Gloucester: CoMedia.

Mulligan, M., Humphrey, K., James, P., Scanlon, C., Smith, P., \& Welch, N. (2007). Creating Communities: Celebrations, arts and wellbeing within and across local communities. Melbourne: VicHealth.

National Advisory Committee on Creative and Cultural Education. (1999). All Our Futures: A Summary. London: DFFE.

Onyx, J. (2014). Social impact, a theoretical model. Cosmopolitan Civil Societies: An Interdisciplinary Journal, 6(1), 1-18.

Onyx, J., Darcy, S., Grabowski, S., Green, J., \& Maxwell, H. (2018). Researching the Social Impact of Arts and Disability: Applying a New Empirical Tool and Method. [journal article]. VOLUNTAS: International Journal of Voluntary and Nonprofit Organizations, 29(3), 574-589. 
Patterson, I. (2000). Developing a Meaningful Identity for People with Disabilities through Serious Leisure Activities. World Leisure Journal, 42(2), 41-51.

QSR International. (2012). NVivo qualitative analysis software package Retrieved 1 March, 2012, from http://www.qsrinternational.com/products_nvivo.aspx

Selkrig, M. (2011). Learning about ourselves from others: Transformation of artists' identities through community-based arts practice. International Journal of Lifelong Education. International Journal of Lifelong Education, 30(5), 577-589.

Singleton, J., \& Darcy, S. (2013). 'Cultural life’, disability, inclusion and citizenship: moving beyond leisure in isolation. Annals of Leisure Research, 16(3), 183-192.

Solvang, P. K. (2018). Between art therapy and disability aesthetics: A sociological approach for understanding the intersection between art practice and disability discourse. Disability \& Society, 33(2), 238-253.

Stebbins, R. A. (1979). Amateurs: Margin Between Work \& Leisure (Vol. 6): SAGE Publications, Incorporated.

Stebbins, R. A. (1982). Serious leisure: A conceptual statement. Pacific Sociological Review, 25(2), 251-272.

Stebbins, R. A. (2005). The role of leisure in arts administration: Occasional Paper Series, Paper No. 1. Retrieved 8 Jan, 2015, from http://aad.uoregon.edu/icas/documents/stebbins0305.pdf

Stebbins, R. A. (2007). Serious Leisure: A Perspective for our Time. New Brunswick, NJ: Transaction Publishers.

Throsby, D., \& Zednik, A. (2011). Multiple job-holding and artistic careers: some empirical evidence. Cultural Trends, 20(1), 9-24.

Veal, A. J. (2017). The serious leisure perspective and the experience of leisure. Leisure Sciences, 39(3), 205-223.

Victorian Office for Disability. (2010). Picture This: Increasing the Cultural Participation of People with a Disability in Victoria: Community Consultation Report and Analysis 2009: Department of Planning and Community Development.

Yin, R. K. (2014). Case Study Research: Design and Methods: Sage publications. 